\title{
Long-term improvement of cardiac function in rats after infarction by transplantation of embryonic stem cells
}

\author{
Jiang-Yong Min, MD \\ Yinke Yang, MD, PhD \\ Matthew F. Sullivan, BS \\ Qingen Ke, MD \\ Kimber L. Converso, RDCS \\ Yu Chen, MD \\ James P. Morgan, MD, PhD \\ Yong-Fu Xiao, MD, PhD
}

\footnotetext{
From the Stem Cell Research Laboratory, The Charles A. Dana Research Institute and the Harvard-Thorndike Laboratory, Cardiovascular Division, Beth Israel Deaconess Medical Center and Harvard Medical School, Boston, Mass.

Received for publication Dec 21, 2001; revisions requested March 18, 2002; revisions received May 23, 2002; accepted for publication May 28, 2002.

Address for reprints: Yong-Fu Xiao, MD, $\mathrm{PhD}$, Cardiovascular Division, Department of Medicine, Beth Israel Deaconess Medical Center, Harvard Medical School, 330 Brookline Ave, Boston, MA 02215 (Email: yxiao@caregroup.harvard.edu).

J Thorac Cardiovasc Surg 2003;125:361-9

Copyright $(\odot) 2003$ by The American Association for Thoracic Surgery

$0022-5223 / 2003 \$ 30.00+0$

doi: $10.1067 / \mathrm{mtc} .2003 .101$
}

Objective: This study was designed to investigate the feasibility of and potential functional improvement with embryonic stem cell transplantation in rats 32 weeks after myocardial infarction.

Methods: Before cell transplantation, cultured embryonic stem cells were transfected with the complementary DNA of green fluorescent protein to identify engrafted cells in myocardium. Myocardial infarction was induced by ligation of the left coronary artery. Either $3 \times 10^{5}$ mouse embryonic stem cells or an equivalent volume of cell-free medium was injected into injured myocardium within 20 minutes after induction of myocardial infarction.

Results: Embryonic stem cell transplantation significantly increased the survival rate in rats undergoing myocardial infarction during the experimental period of 32 weeks. Hemodynamic and echocardiographic data showed that embryonic stem cell transplantation significantly improved ventricular function relative to the myocardial infarction plus medium control group. Tissue positive for green fluorescent protein was found in the injured myocardium with cell transplantation. The proportion of myocardium positively immunostained by antibodies against $\alpha$-myosin heavy chain and cardiac troponin I was greater in the infarcted area with embryonic stem cell transplantation than in the injured myocardium with medium injection. Single green fluorescent protein-positive cells with a rod shape and clear striations were observed in cardiomyocytes isolated from infarcted hearts with embryonic stem cell transplantation. In addition, the number of blood vessels in injured myocardium was greater in the cell-transplanted myocardial infarction group than in the medium-injected myocardial infarction group.

Conclusions: Engrafted embryonic stem cells differentiated into cardiomyocytes in injured myocardium, caused an angiogenetic effect, and subsequently improved cardiac function during the 32-week observation period.

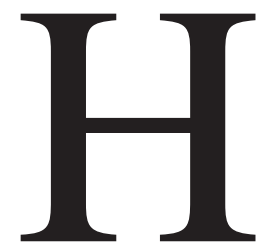

eart failure, which may be the consequence of acute myocardial infarction (MI), is one of the major medical problems facing developed countries. Permanent loss of cardiomyocytes and nonfunctional fibrous scar formation after MI result in irreversible damage of cardiac function. Medical interventions can result in alleviation of the symptoms of cardiac dysfunction in patients with MI. Because a significant percentage of patients have progression to severe heart failure despite medical treatment, however, new and novel therapeutic approaches are always critical and interesting. Heart transplantation is an acceptable 
therapy for end-stage heart failure, but long-term results have been limited by recurrent episodes of rejection and the development of transplanted coronary arteriopathy. The number of patients being listed for heart transplantation continues to escalate, whereas the number of available donors remains relatively unchanged. ${ }^{1}$ Only a small percentage of patients receive heart transplants because of this shortage of donors. New and effective therapies for patients with heart failure are therefore urgently required.

Recent studies have demonstrated that transplantation of cultured cells into damaged myocardium offers a new approach to restoration of the impaired cardiac function in either cryoinjured ${ }^{2,3}$ or infarcted hearts. ${ }^{4-9}$ Engrafted cells have been shown to survive, proliferate, and form gap junctions with the host myocardium.7,10 In contrast, Watanabe and colleagues ${ }^{11}$ found that fetal and neonatal pig cardiomyocytes and the cardiac-derived cell line HL-1 did not survive after grafting into infarcted pig myocardium. However, a recent study in mice showed that intramyocardial transplantation of bone marrow cells not only generated new myocardium but also significantly improved left ventricular (LV) function. ${ }^{4}$ The underlying mechanism of these discrepancies may result from differences in the types of donor cells or the status of the host myocardium at the time of cell transplantation.

Embryonic stem cells, pluripotent cells containing the capacity for unlimited in vitro proliferation, may be useful to cardiogenesis. ${ }^{12}$ Our recent study showed that embryonic stem cell transplantation was feasible in injured myocardium and improved cardiac function in rats with MI 6 weeks after transplantation. ${ }^{13}$ However, the prolonged effects of embryonic stem cell transplantation on postinfarction failing hearts remain to be determined. It is therefore important to know whether the beneficial effects of cell transplantation could last for a longer period. This study investigated the effects of embryonic stem cell transplantation on mortality and cardiac function in rats 32 weeks after MI induction and cell implantation.

\section{Material and Methods}

\section{Embryonic Stem Cell Preparation for Transplantation}

The mouse embryonic stem cell line ES-D3 (American Type Culture Collection, Manassas, Va) was maintained and cultured by the methods previously described. ${ }^{14}$ Briefly, ES-D3 cells were cultured in Dulbecco modified Eagle medium on mitotically inactive mouse embryonic fibroblast feeder cells (American Type Culture Collection). The medium was supplemented with $15 \%$ fetal bovine serum, 0.1-mmol/L $\beta$-mercaptoethanol (Sigma, St Louis, Mo), and $10^{3} \mathrm{U} / \mathrm{mL}$ of leukemia inhibitory factor-conditioned medium (Life Technologies, Inc, Rockville, Md) to suppress differentiation. To initiate differentiation, embryonic stem cells were dispersed with trypsin and resuspended in the medium without supplemental leukemia inhibitory factor and cultured with the hanging drops method (approximately 400 cells per $20 \mu \mathrm{L}$ ) for 5 days. They were then seeded into 100 -mm cell culture dishes.
Beating cardiomyogenic clusters were dissected by use of a sterile micropipette and recultured for another 2 days at $37^{\circ} \mathrm{C}$ in a $98 \%$ humidified atmosphere with 5\% carbon dioxide. Action potentials recorded in 2-week cultured beating embryonic stem cells (data not shown) were similar to those in cultured neonatal mouse cardiomyocytes..$^{13}$

Before transplantation, cells dissected from beating clusters were transfected with green fluorescent protein (GFP), a marker for identification of engrafted cells from host myocytes in injured myocardium. Plasmids with an immediate-early (IE) gene of human cytomegalovirus (CMV) promoter-enhancer driving GFP gene $(5.7 \mathrm{~kb})$ and Gene PORTER transfection reagent were obtained from Gene Therapy Systems Inc (San Diego, Calif). Embryonic stem cells $\left(2 \times 10^{5}\right.$ cells) were plated onto 100 -mm dishes and were grown to $50 \%$ to $60 \%$ confluence on the day of transfection. The GFP transfection efficiency, as detected under fluorescent microscopy, was more than $90 \%$. Two days after GFP transfection, cultured embryonic stem cells were digested with trypsin and resuspended in Joklik modified medium (Sigma) with a density of $10^{7}$ cells $/ \mathrm{mL}$ for cell transplantation. We observed under microscopy that about $40 \%$ to $50 \%$ of the cells used for transplantation were beating. In addition, after 11 days of culture by the hanging drops method without micropipette dissection of beating cells, flow cytometry revealed that $26 \% \pm 1.2 \%$ (mean \pm SEM, $\mathrm{n}=5$ runs) of embryonic stem cells were positive for cardiac $\alpha$-myosin heavy chain $(\alpha-\mathrm{MHC})$.

\section{Experimental Myocardial Infarction and Embryonic Stem Cell Transplantation}

Experiments were performed in male Wistar rats (Charles River Laboratories, Inc, Wilmington, Mass) with an initial body weight of approximately $300 \mathrm{~g}$. The investigation conformed to the Guide for the Care and Use of Laboratory Animals prepared by the Institute of Laboratory Animal Resources, National Research Council, and published by the National Academy Press, revised 1996 (NIH Publication No. 85-23). The protocol was approved by our institutional animal care committee. MI was created by ligation of the left coronary artery as previously described elsewhere. ${ }^{15}$ Within 20 minutes after MI induction, $3 \times 10^{5}$ embryonic stem cells in $30 \mu \mathrm{L}$ medium were injected with a tuberculin syringe into three different sites in infarcted hearts. Two injection sites were at the border of the ischemic area, and the other was in the middle of the injured area. The number of embryonic stem cells injected here was in the range $(30,000$ to 500,000 cells/animal) transplanted by other researchers in animals after MI. ${ }^{4}$ Control rats with MI received the exact volume of the cell-free medium as received by the rats treated with embryonic stem cell transplantation. No experimental rats were treated with immunosuppressants during the 32-week follow-up, despite the xenogenic cell transplantation.

Survivals were evaluated in all groups during the 32 -week follow-up. The study comprised of the following groups: rats with MI that received transplanted embryonic stem cells (MI plus embryonic stem cells, $\mathrm{n}=26$ ), control rats with $\mathrm{MI}$ injected with an exact volume of the cell-free medium (MI plus medium, $\mathrm{n}=$ 31 ), and a sham operation control group with neither ligation of the coronary artery nor intramyocardial injection (sham control, $\mathrm{n}=$ 23). 


\section{Echocardiographic Study}

Thirty-two weeks after transplantation, the animals (5 for each group) were anesthetized with pentobarbital. The echocardiographic procedure was performed as previously described elsewhere. ${ }^{16}$ A commercially available echocardiographic system equipped with a 12.5-MHZ probe (Agilent Sonos 5500; Agilent Technologies, Palo Alto, Calif) was used in our experiments. Initially, a 2-dimensional short-axis view of the LV was obtained at the level of the papillary muscles. After optimizing gain settings and ensuring that the image was on axis, M-mode tracings were recorded through the anterior and posterior LV walls at a paper speed of $100 \mathrm{~mm} / \mathrm{s}$. This orientation was chosen to allow delineation of wall thickness and motion in infarcted and noninfarcted territories. The results were recorded on optical disks, and the M-mode tracings were analyzed. LV mass was calculated with a cube formula. Relative anterior wall thickness, relative posterior wall thickness, and LV internal dimensions were measured from at least three consecutive cardiac cycles. We also used endocardial fractional shortening and midwall fractional shortening as indices to estimate LV systolic function.

\section{Measurement of Hemodynamics}

In another series of experiments, rats $(\mathrm{n}=8$ in sham control group, $\mathrm{n}=8$ in MI plus medium group, and $\mathrm{n}=9$ in MI plus embryonic stem cells group) were anesthetized again with pentobarbital at 32 weeks after MI induction and cell transplantation. Hemodynamic measurements were performed in vivo with a modification of a method described previously. ${ }^{13,16}$ Briefly, a carotid artery of a rat (anesthetized by intraperitoneal administration of pentobarbital at $60 \mathrm{mg} / \mathrm{kg}$ ) was isolated and cannulated with a $3 \mathrm{~F}$ high-fidelity microtip catheter connected to a pressure transducer (Millar Instruments, Inc, Houston, Tex). The Millar catheter was carefully advanced into the LV. LV systolic and end-diastolic pressures, the maximum rate of $\mathrm{LV}$ systolic pressure rise $\left(+\mathrm{dP} / \mathrm{dt}_{\max }\right)$, and heart rate were monitored and recorded on a chart strip recorder. Rats were allowed to breathe spontaneously during hemodynamic measurements. After hemodynamic measurements, the rat was killed and the heart was rapidly excised. The LV, including the septum, was weighed and normalized for body weight. The ratio was calculated as index of hypertrophy.

\section{Measurement of Infarct Size, Identification of Transplanted Cells, and Histologic Analysis}

Under pentobarbital anesthesia $(100 \mathrm{mg} / \mathrm{kg}$ administered intraperitoneally), the rats ( $\mathrm{n}=11$ in the sham control group, 12 in the MI plus medium group, and 10 in the MI plus embryonic stem cells group) were killed to evaluate morphologic characteristics and to identify the engrafted cells. The hearts were quickly removed and dissected into four transverse sections from apex to base. Subsequently, the transverse sections were embedded in tissue-freezing medium. Partial 5- $\mu \mathrm{m}$ transverse slices from each section were prepared for hematoxylin and eosin staining, and the images were digitized. Infarct size was calculated by dividing the sum of the planimetered endocardial and epicardial circumferences of the infarcted area by the sum of the total epicardial and endocardial circumferences of the LV. ${ }^{17}$

The survival of engrafted cells was identified by GFP-positive tissue in frozen sections made from hearts with MI. Transforma- tion of cardiaclike cells from engrafted embryonic stem cells was verified by antibody immunostaining for cardiac $\alpha$-MHC and cardiac troponin I (TnI). Briefly, frozen tissue sections were fixed in acetone at $4{ }^{\circ} \mathrm{C}$ for 10 minutes and incubated separately with a goat polyclonal immunoglobulin $\mathrm{G}$ anti-TnI antibody (Santa Cruz Biotechnology, Inc, Santa Cruz, Calif) or a mouse anti- $\alpha$-MHC monoclonal antibody (Berkeley Antibody Co, Richmond, Calif) for 60 minutes at room temperature. After washing with phosphate-buffered saline solution, sections were incubated with a rabbit antigoat conjugated rhodamine immunoglobulin $\mathrm{G}$ for $\mathrm{TnI}$ or a goat antimouse conjugated fluorescein immunoglobulin $\mathrm{G}$ for $\alpha$-MHC (Pierce Chemical Company, Rockford, Ill). Immunostaining was performed on serial sections of hearts with MI. To verify the survival and transdifferentiation of engrafted cells, single cardiomyocytes were enzymatically isolated from hearts $(n=4)$ at 32 weeks after MI induction and cell transplantation. The detailed isolation method is described in a previous report. ${ }^{18}$

\section{Measurement of Capillary Density}

The effect of embryonic stem cell transplantation on angiogenesis was evaluated by counting the number of capillary vessels ${ }^{3}$ within the infarcted zone from frozen sections with hematoxylin and eosin staining under light microscopy. A capillary vessel was defined as a vessel with a diameter less than $20 \mu \mathrm{m}$. The number of capillaries was counted under microscopy ( $\times 400$ magnification) for five random fields in the infarcted area and presented as the mean of blood vessels per unit area $\left(0.2 \mathrm{~mm}^{2}\right)$.

\section{Data Analysis}

All values are presented as mean \pm SE. Data collected at the end of the 32-week follow-up period were evaluated by 1-way analysis of variance. If analysis of variance showed a significant difference, an unpaired Student $t$ test was used to compare two individual groups. Survival during the 32 -week observation period was analyzed by standard Kaplan-Meier analysis, and a statistical comparison between survival curves was made with the log-rank test.

\section{Results}

To evaluate the effect of embryonic stem cell transplantation on mortality in animals after MI, the survivals during the 32-week observation period were calculated for the three different animal groups. As Figure 1 shows, transplantation of embryonic stem cells significantly increased survival rate in rats after MI. Only 3 of 26 animals in the MI plus embryonic stem cells group $(11.5 \%)$ died during the entire experiment. In contrast, mortality was much higher among rats with MI injected with the cell-free medium. During the 32-week follow-up period, 7 of 31 rats in the MI plus medium group (22.6\%) died. All moribund rats showed exertional dyspnea and decreased mobility at 6 weeks after MI, with ascites and pleural effusions seen during necropsy. One rat from the MI plus embryonic stem cells group and 2 from the MI plus medium group died within the first week after MI and showed none of these signs. Kaplan-Meier analysis (Figure 1) demonstrated a significant increase (logrank $=3.86, P<.05)$ in survival in the rats transplanted 


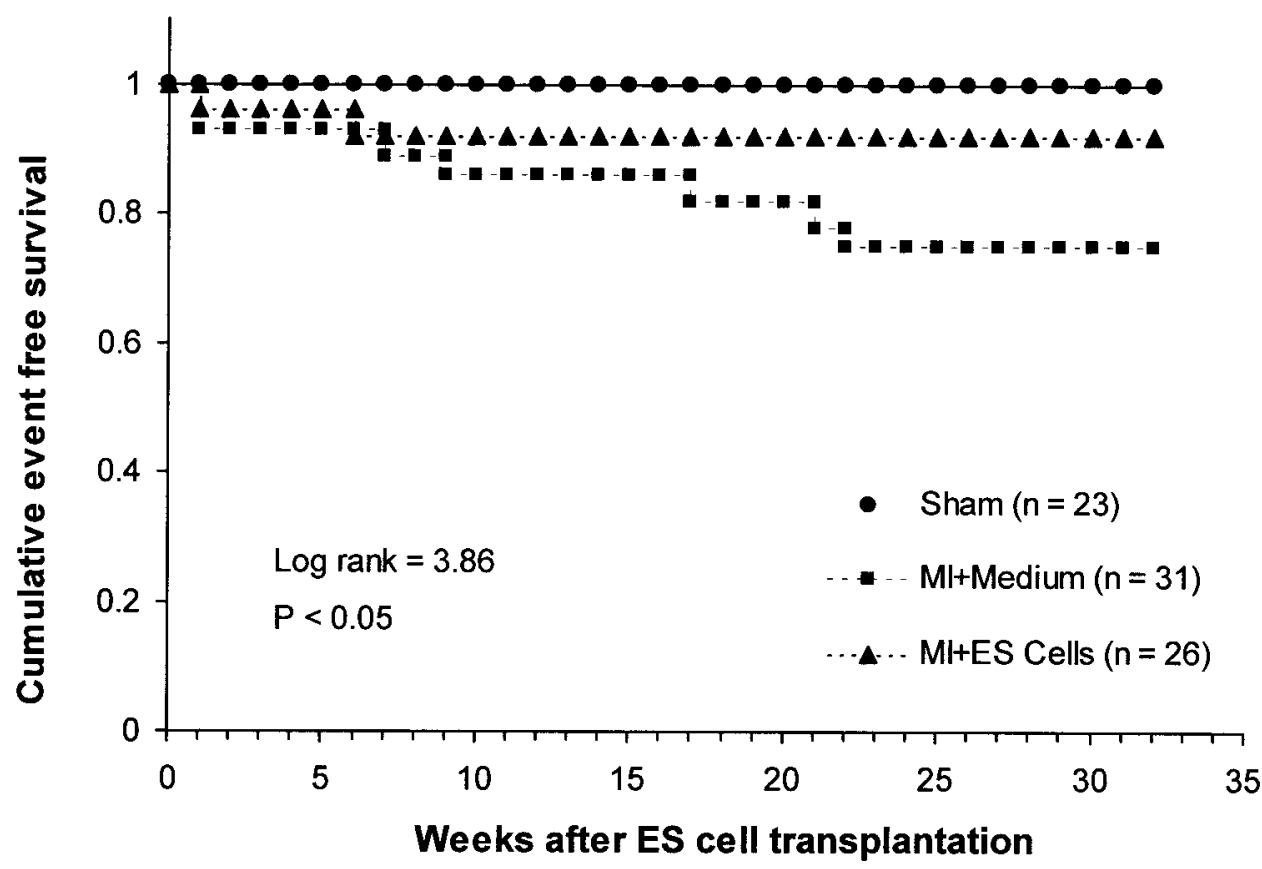

Figure 1. Kaplan-Meier survival curves for sham control group (Sham, circles) and rats with induced MI injected with cell-free medium (MI+Medium, squares) or transplanted with embryonic stem cells (MI+ES Cells, triangles) during 32-week trial. Compared with MI plus medium group, rats with MI plus embryonic stem cell transplantation had significantly increased survival.

TABLE 1. General characteristics of sham operation group and groups with MI

\begin{tabular}{|c|c|c|c|}
\hline & $\begin{array}{l}\text { Sham operation } \\
\qquad(\mathrm{n}=\mathbf{8})\end{array}$ & $\begin{array}{l}\text { MI plus } \\
\text { medium } \\
(n=8)\end{array}$ & $\begin{array}{c}\text { MI plus } \\
\text { embryonic stem } \\
\text { cells } \\
(n=9)\end{array}$ \\
\hline Body weight $(\mathrm{g})$ & $623.6 \pm 14.2$ & $619.5 \pm 13.9$ & $598.5 \pm 16.4$ \\
\hline LV weight (mg) & $978.3 \pm 9.9$ & $1224.3 \pm 12.7^{*}$ & $1143.6 \pm 8.9 \dagger$ \\
\hline $\begin{array}{l}\text { LV weight/body } \\
\text { weight ratio } \\
(\mathrm{mg} / \mathrm{g})\end{array}$ & $1.5 \pm 0.15$ & $2.1 \pm 0.12^{*}$ & $1.7 \pm 0.11$ \\
\hline Infarct size (\%) & & $37.2 \pm 1.5$ & $30.6 \pm 1.1 \dagger$ \\
\hline
\end{tabular}

Values are mean \pm SE. Infarct size was measured in 5 rats in each group. Animals in sham operation group were measured at 32 weeks after operation; rats in $\mathrm{Ml}$ groups were measured at 32 weeks after $\mathrm{Ml}$ and either injection with cell-free medium or embryonic stem cell transplantation.

${ }^{*} P<.05$ versus sham operation group.

$\dagger P<.05$ versus $\mathrm{Ml}$ plus medium group.

with embryonic stem cells compared with the animals injected with the cell-free medium.

Table 1 summarizes the effects of embryonic stem cell transplantation on LV mass and infarct area in rats at 32 weeks after the MI induction and cell transplantation. LV weight and the ratio of LV weight to body weight were significantly increased in the MI plus medium group relative to the sham control group. However, embryonic stem cell transplantation significantly reduced not only the severity of LV hypertrophy but also the area of infarction in the rats with MI. In addition, the LV systolic pressure and maximum rising rate of pressure $\left(+\mathrm{dP} / \mathrm{dt}_{\max }\right)$ were significantly recovered in the rats transplanted with embryonic stem cells (Figure 2) relative to the medium-injected group. The LV end-diastolic pressure was significantly lower in the MI plus embryonic stem cells group than in the rats injected with the cell-free medium. There were no significant differences in heart rate among the three groups $(373 \pm 8$ beats/min in sham control group, $390 \pm 12$ beats/min in MI plus medium group, and $382 \pm 9$ beats/min in MI plus embryonic stem cells group). These results indicate that embryonic stem cell transplantation significantly improved LV function without an alteration of heart rate at 32 weeks after MI induction and cell implantation.

Table 2 and Figure 3 show the results of echocardiographic assessment of cardiac function in rats at 32 weeks after MI and embryonic stem cell implantation. The LV cavity became dilated in infarcted rat hearts with injection of the cell-free medium. Enlargement of LV cavity dimensions in infarcted hearts resulted in significant decreases in anterior and posterior wall thicknesses and subsequently produced reductions in endocardial and midwall fractional shortenings. The ratio of LV mass to body weight was significantly less at 32 weeks after MI in the rats trans- 
A

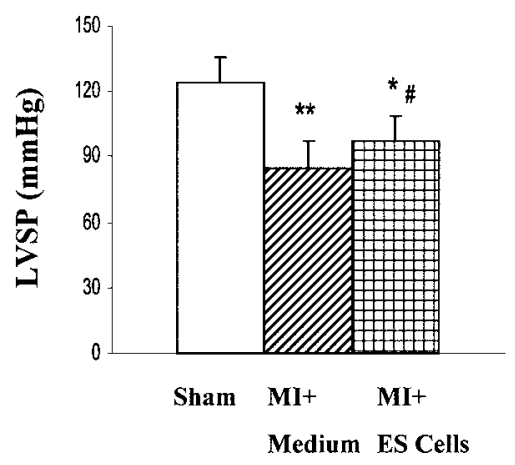

B

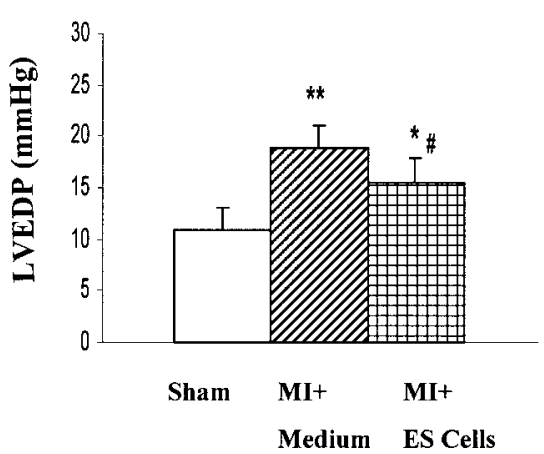

C

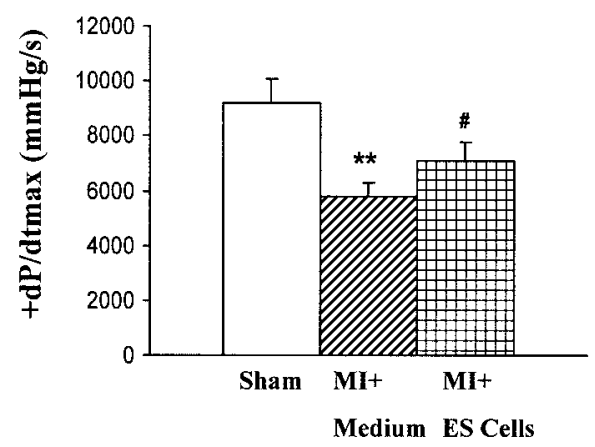

Figure 2. Embryonic stem cell transplantation significantly improved LV function in rats after MI. A, LV systolic pressure (LVSP); B, LV end-diastolic pressure (LVEDP); C, rate of peak LV systolic pressure rise $\left(+d P / d t_{\text {max }}\right.$ ). Measurements were conducted 32 weeks after MI induction. Sham, Sham operation group $(\mathrm{n}=10)$; MI+Medium, rats with $M I$ injected with cell-free medium $(\mathrm{n}=9$ ); $M I+E S$ Cells, rats with MI transplanted with embryonic stem cells $(\mathrm{n}=10)$. Asterisk indicates $P<.05$ versus sham control; double asterisk indicates $P<.01$, versus sham control; crosshatch indicates $\boldsymbol{P}<.05$ versus MI plus medium.

TABLE 2. Echocardiographic measurement of LV function in vivo

\begin{tabular}{|c|c|c|c|}
\hline & $\begin{array}{l}\text { Sham operation } \\
\qquad(\mathrm{n}=8)\end{array}$ & $\begin{array}{l}\text { MI plus medium } \\
\quad(\mathrm{n}=\mathbf{8})\end{array}$ & $\begin{array}{c}\text { MI plus } \\
\text { embryonic stem } \\
\text { cells }(n=9)\end{array}$ \\
\hline Posterior wall thickness (\%) & $79.2 \pm 8.5$ & $46.2 \pm 3.5^{*}$ & $59.5 \pm 4 \dagger \ddagger$ \\
\hline Anterior wall thickness $(\%)$ & $64.4 \pm 7.5$ & $39.5 \pm 4.5 \dagger$ & $54.6 \pm 5 \ddagger$ \\
\hline LV diastolic dimension (mm) & $8.0 \pm 0.2$ & $10.5 \pm 0.3^{*}$ & $8.6 \pm 0.3 \ddagger$ \\
\hline LV systolic dimension (mm) & $5.1 \pm 0.2$ & $7.7 \pm 0.4^{*}$ & $6.2 \pm 0.3 \dagger \ddagger$ \\
\hline Endocardial fractional shortening (\%) & $36.7 \pm 1.3$ & $24.2 \pm 1.2 \dagger$ & $31.0 \pm 0.8 \ddagger$ \\
\hline Midwall fractional shortening (\%) & $21.1 \pm 1.3$ & $14.5 \pm 1.1$ & $17.6 \pm 0.6$ \\
\hline LV mass $(\mathrm{g})$ & $0.92 \pm 0.1$ & $1.38 \pm 0.2^{*}$ & $1.09 \pm 0.1 \ddagger$ \\
\hline LV mass/body weight $(\mathrm{mg} / \mathrm{g})$ & $1.5 \pm 0.1$ & $2.3 \pm 0.1^{*}$ & $1.8 \pm 0.3 \ddagger$ \\
\hline
\end{tabular}

Values are mean $\pm \mathrm{SE}$. Each group represents 5 rats.

${ }^{*} P<.01$ versus sham operation group.

$\dagger P<.05$ versus sham operation group.

$\ddagger P<.05$ versus $\mathrm{Ml}$ plus medium group.

planted with embryonic stem cells than in the animals that received medium injection. The LV anterior and posterior walls in the infarcted zone were thicker in the rats with cell transplantation than in the rats with medium injection. In addition, LV diastolic and systolic dimensions were decreased in rats with cell transplantation.

To identify the survival of engrafted cells in damaged myocardium, fresh-frozen sections were prepared from hearts at 32 weeks after embryonic stem cell transplantation. Figure 4, A, shows that richly GFP-positive spots were detected under fluorescent microscopy in myocardium with cell implantation. Those engrafted cell spots were found either in the middle of the infarcted zone or in the border zone between normal and infarcted myocardium. This result suggests that engrafted cells, or at least some proportion of them, survived well in injured myocardium at 32 weeks after MI induction and embryonic stem cell transplantation. In addition, GFP-positive cells were observed in single myocytes isolated from hearts at 32 weeks after embryonic stem cell transplantation (Figure 4, B). These GFP-positive cells were rod shaped with clear striations, characteristic of adult mammalian cardiomyocytes (Figure $4, C$ ). The average number of GFP-positive cells isolated from 4 rats after the 32-week follow-up was 1,929,500 $\pm 119,907$ out of a total average of $16,263,900 \pm 1,218,478$ myocytes. The percentage of GFP-positive cells among total isolated LV myocytes was $11.9 \%$, which is higher than the percentage of GFP-positive cells in rat hearts at 6 weeks after MI and embryonic stem cell transplantation (7.3\%). ${ }^{13}$ Hematoxylin and eosin staining of myocardial sections showed engrafted cells in injured myocardium at 32 weeks after embryonic stem cell transplantation (Figure 5, C). More $\alpha$-MHC (Fig- 


\section{Sham}

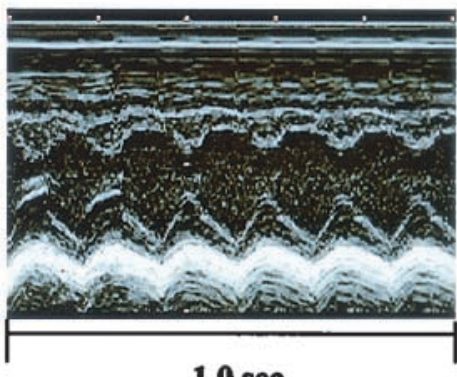

MI+Medium

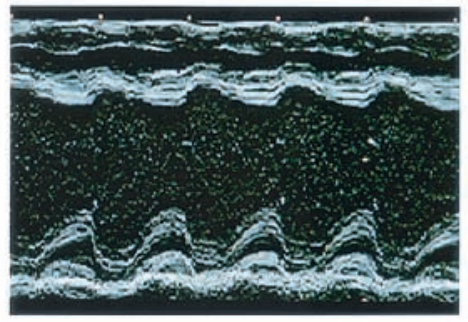

\section{MI+ES Cells}

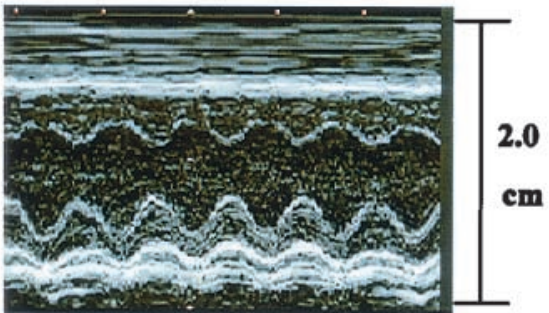

Figure 3. Representative echocardiographic recordings in rat with sham operation (Sham), rat with MI and injection of cell-free medium (MI+Medium), and rat with $\mathrm{MI}$ and transplantation of embryonic stem cells (MI+ES Cells). Anterior and posterior walls were thinned and hypokinetic, whereas LV cavity became dilated in rat heart with injection of cell-free medium. In contrast, embryonic stem cell transplantation improved ventricular wall contractility and reduced LV dilation relative to hearts with MI and injection of cell-free medium.
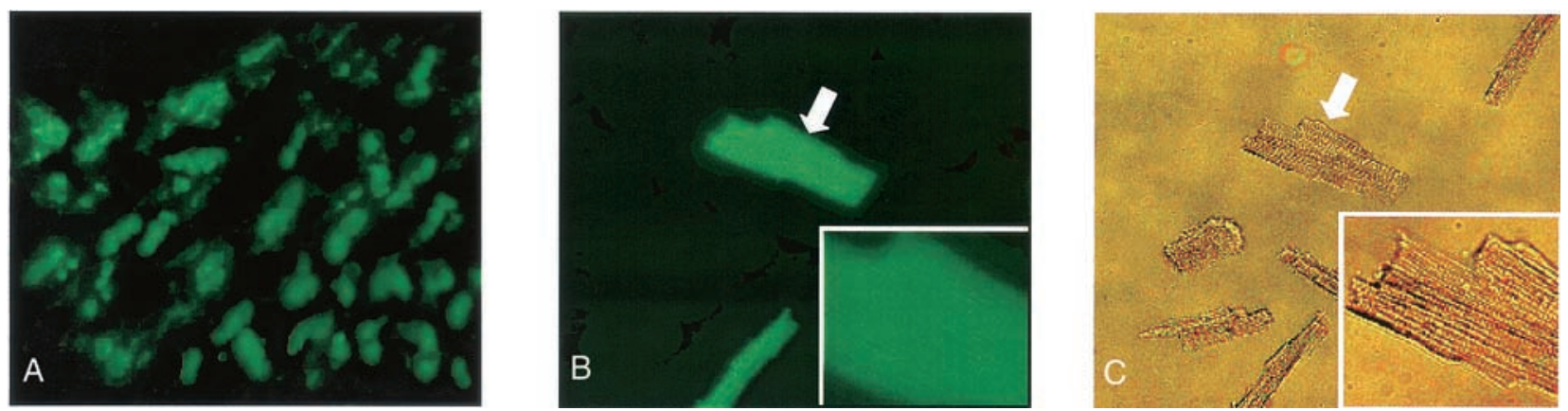

Figure 4. GFP-positive spots and single cells from myocardium with MI plus cell transplantation. A, Under fluorescent microscopy (original magnification $\times 200$ ), frozen section shows strong GFP-positive tissue in cellimplanted myocardium at 32 weeks after MI induction and cell transplantation. B, Single GFP-positive cells isolated from heart with $\mathrm{MI}$ were verified under fluorescent microscopy (original magnification $\times 200$ ). Thirty-two weeks previously heart had MI induced and was transplanted with embryonic stem cells. C, This panel corresponds to panel B and shows host and GFP-positive cardiomyocytes under phase-contrast microscopy. Both GFP-negative and GFP-positive cells were rod shaped with clear striations (original magnification $\times 200$ ). Insets in $B$ and $C$ are enlargements of areas indicated by arrows.

ure $6, C$ ) and cardiac TnI (Figure $6, F$ ) were found in the cell-transplanted specimens, but only a limited number of sections were studied. These data suggest that engrafted embryonic stem cells not only survived in myocardium as long as 32 weeks after MI induction and cell transplantation but also differentiated into mature cardiomyocytes.

To examine whether transplanted embryonic stem cells induced an angiogenetic effect in injured myocardium, the density of blood vessels was calculated in the infarcted area with hematoxylin and eosin staining. The number of capillaries increased significantly $(P<.01)$ after 32 weeks in injured myocardium in rats with embryonic stem cell transplantation relative to medium injection (Figure 7). This result indicates that engrafted embryonic stem cells may cause or enhance neovascularization in injured myocardium.

\section{Discussion}

The major observation of this study was the improvement in cardiac function after 32 weeks in rats that received transplanted embryonic stem cells. Several studies have shown that transplantation of neonatal cardiomyocytes, fetal cardiomyocytes, and adult bone marrow cells can regenerate myocardium in scar or infarcted tissue and improve cardiac function in experimental animal models. ${ }^{4-9}$ Electron microscopy has revealed that nascent intercalated disks may be formed in injured myocardium between engrafted cardiomyocytes and host cells. ${ }^{10}$ Koh and coworkers ${ }^{19}$ further 

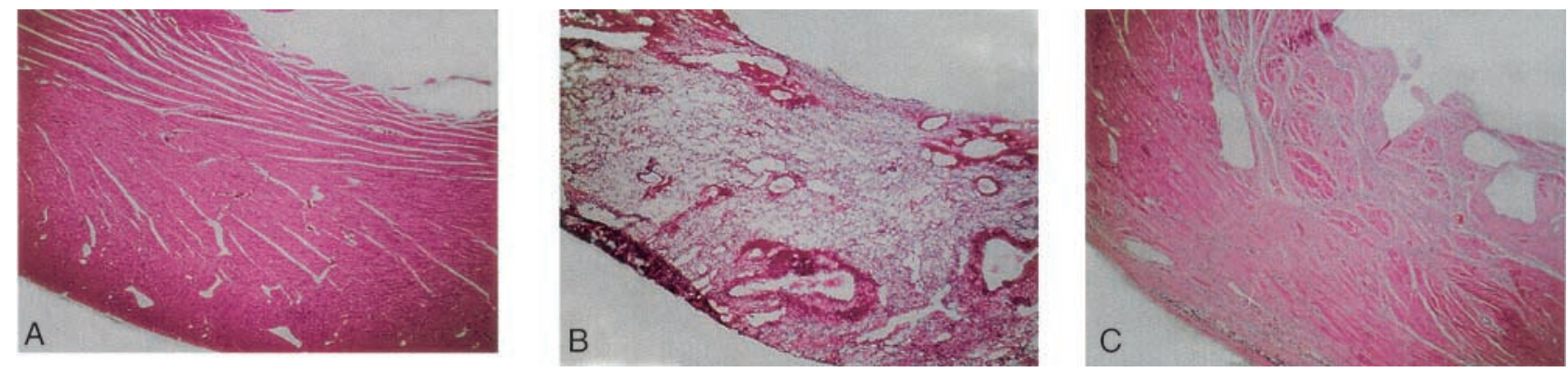

Figure 5. Engrafted embryonic stem cells are shown with hematoxylin-eosin staining in myocardium at 32 weeks after MI and cell transplantation. A, From rat with sham operation; B, from rat with injection of cell-free medium; C, from rat with transplantation of embryonic stem cells. Original magnification $\times 40$.
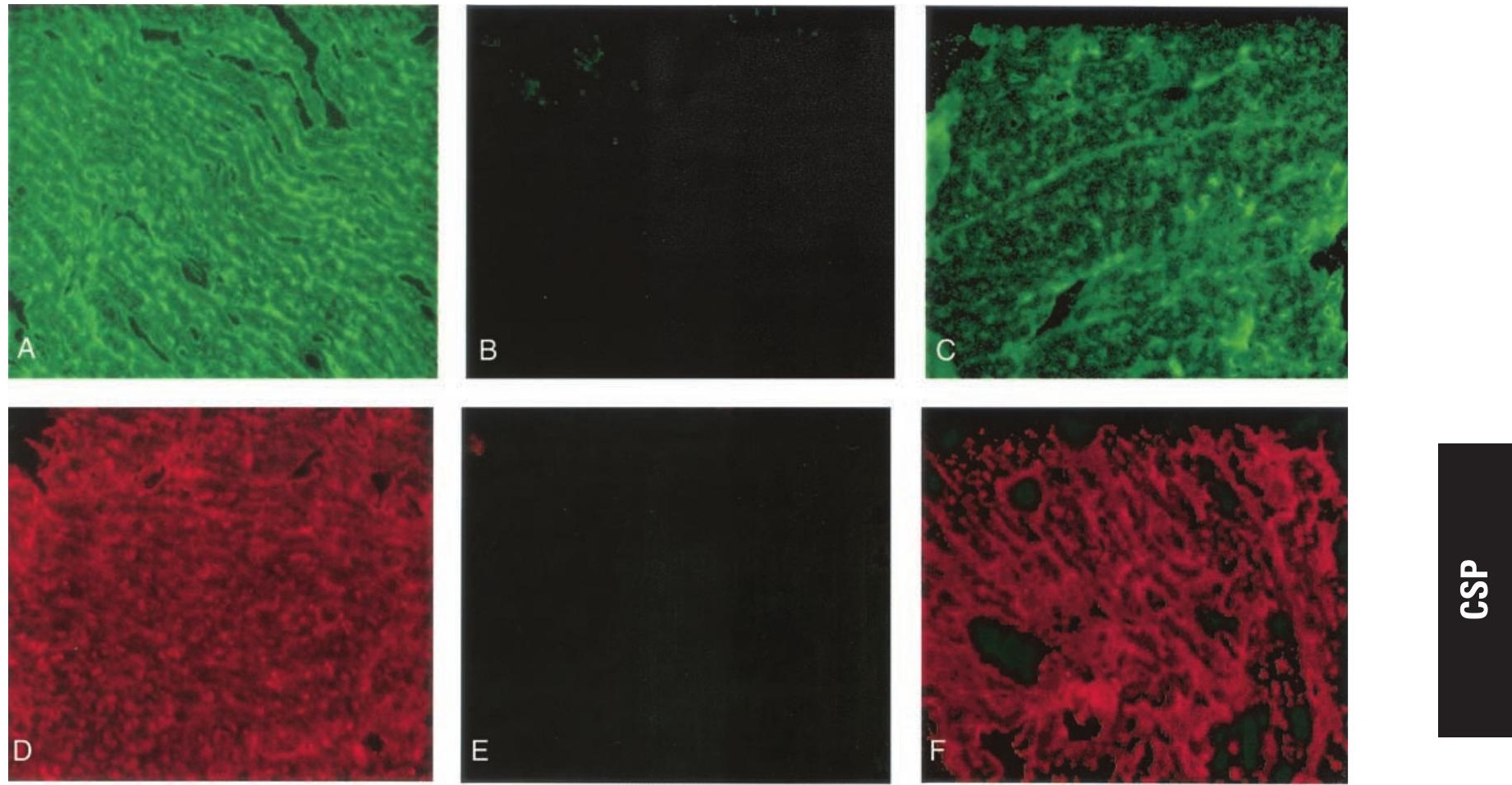

Figure 6. Immunostaining for $\alpha$-MHC and cardiac $\mathrm{Tnl}$ in rat myocardium. Myocardium in sham control group was stained positively and evenly by antibodies against $\alpha$-MHC $($ A, original magnification $\times 200)$ and cardiac $T n I(D$, original magnification $\times 200$ ). Areas in myocardium with $\mathrm{MI}$ and injection of cell-free medium stained positively by antibodies against $\alpha$-MHC (B) and cardiac Tnl (E) were smaller. In contrast, areas in MI myocardium with transplantation of embryonic stem cells stained with antibodies against $\alpha$-MHC (C, original magnification $\times 200)$ and cardiac $\mathrm{Tnl}(\mathrm{F}$, original magnification $\times \mathbf{2 0 0})$ were significantly larger.

confirmed gap junctions between engrafted cells and host myocytes. However, no data have shown the optimal cell type for cell therapy in the heart. Cardiomyogenic cells derived from embryonic stem cells may be a viable source for cell transplantation. Embryonic stem cells have been shown to differentiate spontaneously into the derivatives of all three primary germ layers ${ }^{20}$ and to retain the ability to differentiate into most cell types of the body, including cardiomyocytes. ${ }^{12}$ Furthermore, embryonic stem cells cultured within embryonic bodies can reproduce highly specialized phenotypes of cardiac tissue. ${ }^{21}$ In our study, engrafted embryonic stem cells survived in injured myocardium.

Our previous ${ }^{13}$ study showed that transplanted embryonic stem cells could differentiate into cardiomyocytes and subsequently enhance ventricular function at 6 weeks after 


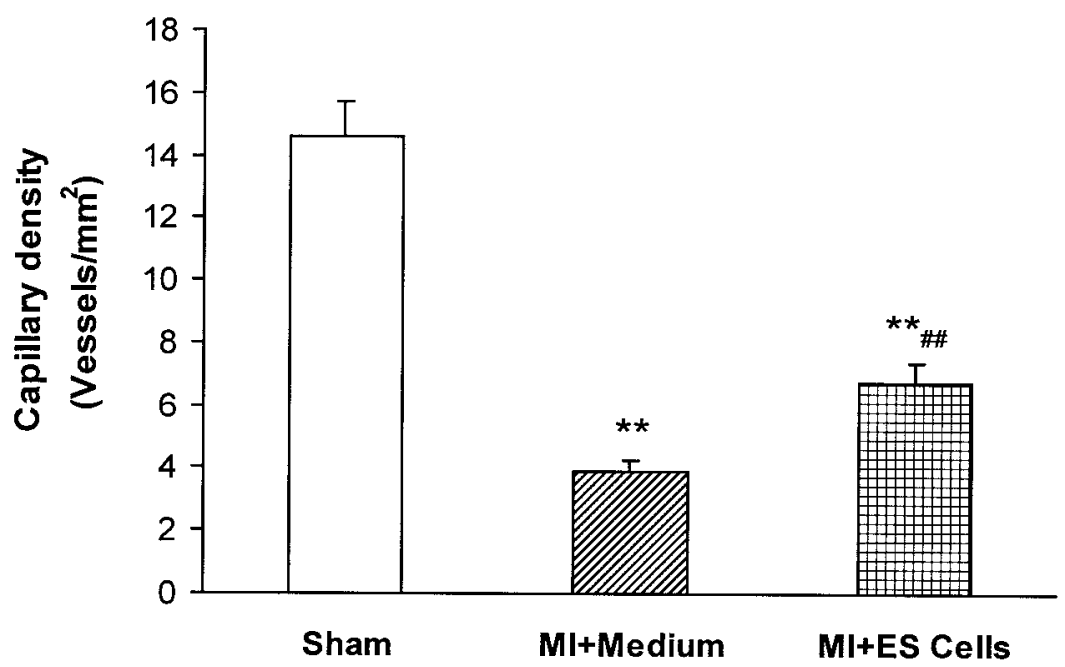

Figure 7. Numeric densities of capillaries (vessels $/ 0.2 \mathrm{~mm}^{2}$ ) in myocardium from sham control group (Sham), MI plus medium group (MI+Medium), and MI plus embryonic stem cells group (MI+ES Cells) at 32 weeks after MI induction. In hearts with MI, embryonic stem cell transplantation significantly increased capillary density relative to injection of cell-free medium. Double asterisk indicates $P<.01$ versus sham control group; double crosshatch indicates $\boldsymbol{P}<.01$ versus $\mathrm{MI}$ plus medium group.

MI induction and cell implantation. In this study engrafted embryonic stem cells improved cardiac function, which was evaluated by hemodynamic and echocardiographic measurements, for a much longer period. We did not perform simultaneous pressure and volume measurements, however, and we therefore did not evaluate load-independent indices of ventricular function. The survival of engrafted cells in injured myocardium was confirmed by the finding of strongly GFP-positive tissues in myocardium at 32 weeks after MI induction and cell transplantation. Single GFPpositive cells isolated from hearts with embryonic stem cell transplantation were rod shaped with clear striations. In addition, immunostaining for $\alpha$-MHC and cardiac TnI showed a higher proportion of injured myocardium with embryonic stem cell transplantation than with medium injection. Our data strongly suggest that the improvement in cardiac function may result from transformation of cardiomyocytes from implanted embryonic stem cells. Because we did not evaluate enough sections in individual animals to quantitate the extent of the engrafted embryonic stem cell transdifferentiation, however, more experiments are certainly required. In addition, histologic examination did not show significant evidence of immunorejection of engrafted cells. Neither infiltration of lymphocytes and macrophages (cell-mediated immunoreaction) nor antibody-mediated vascular damage was observed in hearts at 32 weeks after MI induction and cell transplantation. The underlying mechanism of the weak immunorejection has not been determined. A possible explanation is that the small quantity of transplanted embryonic stem cells may not be able to trigger an immunorejection, because embryonic stem cells express few membrane surface antigens. ${ }^{22}$ From our previous experiments, ${ }^{23}$ we learned that the surface membrane of human embryonic kidney cells does not express CD4 and CD8, which are crucial for immunoreaction. Additional experiments are surely required to understand the lack of immunorejection in animals transplanted with embryonic stem cells. Furthermore, we cannot be certain whether rejection reduced the beneficial effects of embryonic stem cell transplantation because of deficiencies in quantitative assessment of the extent of rejection.

Single cardiomyocytes showed that $11.9 \%$ of enzymatically isolated cells from LVs in the rats at 32 weeks after MI induction and cell transplantation were GFP positive. This percentage is greater than that in rats at 6 weeks after MI and cell transplantation (7.3\%). ${ }^{13}$ However, the functional improvements were similar in the rats at 6 and 32 weeks after MI and cell transplantation. This result suggests that the improvement of cardiac function reached a limited level after transplantation of a certain amount of embryonic stem cells. Damaged myocardial regions with enriched grafted cells were accompanied by new blood vessels found in our experiments, thus an angiogenetic effect may be crucial to the survival of transplanted cells. New blood supply to damaged myocardium may provide nutrition to implanted cells, allow an avenue for removal of cellular debris during primary injury, and also rescue some host myocytes injured in the ischemic area. These effects may help the heart to improve its function. The mechanism of the angiogenetic effect caused by embryonic stem cell transplantation remains to be determined. However, it is possible that transplanted embryonic stem cells may deliver strong signals, 
such as endothelial growth factors and insulinlike growth factors, to stimulate neovascularization in the surrounding tissues or that a portion of the implanted embryonic stem cells may transdifferentiate into the cell sources for revascularization. It has been reported that embryonic stem cells express vascular endothelial growth factors and cause an angiogenetic effect after cell implantation in infarcted myocardium. ${ }^{24}$ In rat experiments of myocardial cryoinjury, Tomita and associates ${ }^{3}$ counted capillary density and found that the number of capillaries was significantly greater in rats with transplantation of autologous bone marrow cells than in control animals. Neovascularization therefore may result in a reduction in infarct size of the heart, as shown by this study.

In summary, transplantation of embryonic stem cells caused a long-term improvement of heart function in rats after MI. This improvement may have resulted from transformation of cardiac myocytes and blood vessels by engrafted embryonic stem cells. This novel approach may offer insight into potential clinical therapy for MI and heart failure.

\section{References}

1. Lang ND, Borkon AM. The dilemma of too few hearts. $J$ Transpl Coord. 1999;9:277-80.

2. Li RK, Jia ZQ, Weisel RD, Mickel DA, Zhang J, Mohabeer MK, et al. Cardiomyocyte transplantation improves heart function. Ann Thorac Surg. 1996;62:654-61.

3. Tomita S, Li RK, Weisel RD, Mickle DA, Kim EJ, Sakai T, et al. Autologous transplantation of bone marrow cells improves damaged heart function. Circulation. 1999;100 Suppl 2:II247-56.

4. Orlic D, Kajstura J, Chimenti S, Jakoniuk I, Anderson SM, Li B, et al. Bone marrow cells regenerate infarcted myocardium. Nature. 2001; 410:701-5.

5. Leor J, Patterson M, Quinones MJ, Kedes LH, Kloner RA. Transplantation of fetal myocardial tissue into the infarcted myocardium of rat: a potential method for repair of infarcted myocardium? Circulation. 1996;94 Suppl 2:II332-6.

6. Li RK, Mickle DA, Weisel RD, Jia ZQ, Kim EJ, Tomita S, et al. Autologous porcine heart cell transplantation improved heart function after a myocardial infarction. J Thorac Cardiovasc Surg. 2000;119: $62-8$.

7. Reinecke H, Zhang M, Bartosek T, Murry CE. Survival, integration, and differentiation of cardiomyocytes grafts: a study of normal and injured rat hearts. Circulation. 1999;100:193-202.
8. Scorsin M, Marotte F, Sabri A, Le Dref O, Demirag M, Samuel JL, et al. Can grafted cardiomyocytes colonize periinfarction myocardial areas? Circulation. 1996;94 Suppl 2:II337-40.

9. Scorsin MS, Hagege AA, Marotte F, Mirochnik N, Copin H, Barboux $\mathrm{M}$, et al. Does transplantation of cardiomyocytes improve function of infarcted myocardium? Circulation 1997;96 Suppl 2:II188-93.

10. Soonpaa MH, Koh GY, Klug MG, Field LJ. Formation of nascent intercalated disks between grafted fetal cardiomyocytes and host myocardium. Science. 1994;264:98-101.

11. Watanabe E, Smith DM Jr, Delcarpio JB, Sun J, Smart FW, Van Meter $\mathrm{CH}$, et al. Cardiomyocyte transplantation in a porcine myocardial infarction model. Cell Transplant. 1998;7:239-46.

12. Robbins J, Doetschan T, Jones WK, Sanchez A. Embryonic stem cells as a model for cardiogenesis. Trends Cardiovasc Med. 1992;2:44-50.

13. Min JY, Yang Y, Liu L, Morgan JP, Xiao YF. Transplantation of embryonic stem cells improves cardiac function in postinfarcted rats. J Appl Physiol. 2002;92:288-96.

14. Smith AG. Culture and differentiation of embryonic stem cells. $J$ Tissue Culture Methods. 1991;13:89-94.

15. Min JY, Sandmann S, Meissner A, Unger T, Simon R. Differential effects of mibefradil, verapamil, and amlodipine on myocardial function and intracellular $\mathrm{Ca}^{2+}$ handling in rats with chronic myocardial infarction. J Pharmacol Exp Ther. 1999;291:1038-44.

16. Litwin SE, Katz SE, Morgan JP, Douglas PS. Serial echocardiographic assessment of left ventricular geometry and function after large myocardial infarction in the rats. Circulation. 1994;89:345-54.

17. Pfeffer JM, Pfeffer MA, Fletcher PJ, Braunwald E. Progressive ventricular remodeling in rat with myocardial infarction. Am J Physiol. 1991;260(5 Pt 2):H1406-14.

18. Xiao YF, Huang L, Morgan JP. Cytochrome P450: a novel system modulating $\mathrm{Ca}^{2+}$ channels and contraction in mammalian heart cells. J Physiol (Lond). 1998;508:777-92.

19. Koh GY, Soonpaa MH, Klug MG, Pride HP, Cooper BJ, Zipes DP. Stable fetal cardiomyocyte grafts in the hearts of dystrophic mice and dogs. J Clin Invest. 1995;96:2034-42.

20. Martin GR. Isolation of a pluripotent cell line from early mouse embryos cultured in medium conditioned by teratocarcinoma stem cells. Proc Natl Acad Sci U S A. 1981;78:7634-8.

21. Hescheler J, Fleishmann BK, Lentini S, Maltsev VA, Rohwedel J, Wobus AM, et al. Embryonic stem cell: a model to study structural and functional properties in cardiomyocytes. Cardiovasc Res. 1997; 36:149-62.

22. O'Shea KS. Embryonic stem cell models of development. Anat Rec. 1999;257:32-41.

23. Xiao YF, Wright SN, Wang GK, Morgan JP, Leaf A. Coexpression with the $\beta 1$ subunit modifies the kinetics and fatty-acid block of $\mathrm{hH}_{1 \alpha}$ $\mathrm{Na}^{+}$channels. Am J Physiol Heart Circ Physiol. 2000;279:H35-46.

24. Yang Y, Min JY, Ke Q, Morgan JP, Xiao YF. Transplantation of embryonic stem cells overexpressing a vascular endothelial growth factor into infarcted myocardium in mice [abstract]. Circulation. 2000;102(Suppl):452. 